\title{
Direct Percutaneous Venous Puncture and Embolization of Giant Perimedullary Arteriovenous Fistulas
}

A. Casasco SUmmaRY: PMAVFs are rare entities that are formed by a direct communication between an artery

L. Guimaraens

H. Cuellar

J. Theron

that feeds the spinal cord and a vein. The goal of treatment is to occlude the shunt; this is done endovascularly either from an arterial or a venous approach. When these approaches are not possible, direct percutaneous puncture of the draining veins may be attempted to embolize the arteriovenous shunt directly.

J. Heredero

ABBREVIATIONS: $\mathrm{AP}=$ anteroposterior; $\mathrm{AVF}=$ arteriovenous fistula; $\mathrm{AVM}=$ arteriovenous malformation; DSA = digital subtraction angiography; ICU = intensive care unit; IV = intravenous; $n$-BCA $=n$-butyl 2-cyanoacrylate; PMAVF = perimedullary arteriovenous fistula

$\mathbf{P}$ MAVFs are rare entities that are formed by a direct communication between an artery that feeds the spinal cord and a vein ${ }^{1}$; they correspond to type IV of the spinal vascular malformations described by Heros et $\mathrm{al}^{2}$ and are subclassified into 3 subtypes according to the size of the shunt. ${ }^{3,4}$ In giant PMAVFs, the shunts are classically described as open canal communications between an artery or dilated arterial collector and ecstatic vein of great size, but sometimes they can be seen as the confluence of several arterial feeders toward the venous collector. The latter angioarchitectural type of giant PMAVF is similar to intracranial arteriovenous fistulas and is called "arteriolo-venous." 5 One of the most constant features of these fistulas is the association with giant ecstatic veins, which are the main drainage of the shunt or in proximity to it. ${ }^{6} \mathrm{Clin}$ ical symptoms of PMAVF are secondary to progressive myelopathy due to venous hypertension, hemorrhage, or mass effect, which eventually results in a major deficit. ${ }^{1,7-9}$ A giant PMAVF with a large feeding artery and draining vein is typically best managed with endovascular therapy, especially if the PMAVF is located above the conus. ${ }^{10-12}$

We present a novel technique for the treatment of a giant PMAVF performed in 2 cases ( 1 lumbar and 1 cervical) in which previous endovascular arterial and venous approaches were unsuccessful and had left the patient with no access to the shunt.

\section{Case 1}

A 17-year-old girl had a history of intraspinal hemorrhage between the $\mathrm{C} 2$ and $\mathrm{C} 5$ segments at age 3, secondary to a complex cervical giant PMAVF fed by the anterior and posterior radiculomedullary arteries. At the time, the patient was treated with partial endovascular embolization with $n$-BCA and recovered well, remaining only with a minor right hemiparesis. In the following years, several attempts to occlude the fistula

Received September 28, 2009; accepted after revision December 10.

From the Department of Endovascular Therapy (A.C., L.G., H.C., J.T., J.H.), Clinica Nuestra Señora del Rosario, Madrid, Spain; and Department of Therapeutic Neuroangiography (L.G.), Hospital General de Cataluña, Barcelona, Spain.

Please address correspondence to Alfredo Casasco, MD, Department of Endovascular Therapy, Clinica Nuestra Señora del Rosario, Madrid, Spain; e-mail: casasco@mimsl.es

Indicates open access to non-subscribers at www.ajnr.org

DOI 10.3174/ajnr.A2025 by arterial and venous approach were made unsuccessfully. At 17 years of age, in an attempt to resolve her problem, we proposed a direct percutaneous puncture of the fistula and embolization. Previous examinations showed that a large venous pouch was present at $\mathrm{C} 3-\mathrm{C} 5$ in a right anterolateral situation and that all the arterial feeders drained into a perimedullary vein communicating with that pouch.

The procedure was performed with the patient under general anesthesia. A 5F introducer was placed in the right femoral artery, and a diagnostic spinal angiography was performed, revealing a giant PMAVF formed by anterior radiculomedullary arteries coming from the right and left vertebral arteries and the left deep cervical artery and also from the posterior radiculopial arteries from both vertebral arteries. All these branches converged into a large perimedullary vein communicating with a right anterolateral venous pouch draining upward into the cerebellar veins and downward to other perimedullary veins.

The diagnostic catheter was positioned in the right vertebral artery because the fistula was best seen from this artery (Fig 1). The patient was positioned in a left oblique position, and a roadmap was obtained to see the venous pouch. With the right C3-C4 neural foramen displayed, we continued to the direct anterolateral percutaneous puncture of the venous pouch through this foramen with the aid of an 18-gauge Abbocath needle catheter (Abbott Laboratories, Abbott Park, Illinois) under biplane roadmapping, until the needle was placed in the center of the venous pouch and we had blood reflux through the needle (Fig 2). Next, we performed DSA with contrast injection through the Abbocath to corroborate the correct position within the venous pouch. A hemostatic valve was placed on the Abbocath and a RapidTransit microcatheter (Cordis, Miami Lakes, Florida) was introduced with the help of a 0.016-inch Glidewire (Terumo, Tokyo, Japan) to catheterize the exact point where the arterial feeders drained into the venous side. Once the microcatheter was in a good position, we embolized the draining vein with coils and glue, achieving the complete occlusion of the fistula and the draining vein (Fig 3). The final control imaging from all the feeders showed the complete occlusion of the PMAVF and the reappearance of normal venous drainage at the cerebellar level (Fig 4).

We withdrew the Abbocath from the venous pouch, injecting glue at the same time to avoid hemorrhage. After the pro- 


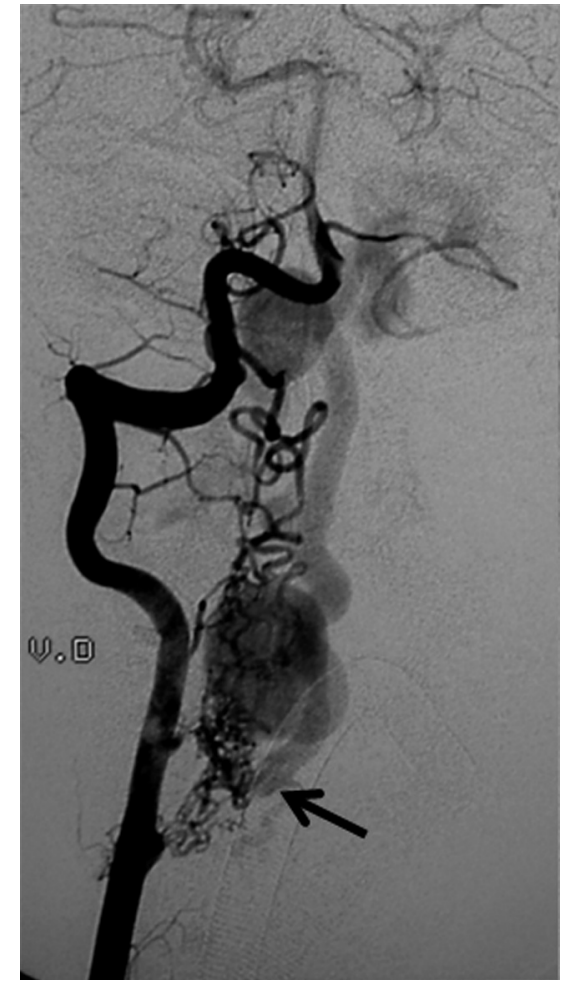

Fig 1. Right vertebral artery DSA. Giant perimedullar AVF of the arteriovenous type (confluence of all arterial pedicles toward a single vein). The venous collector (black arrow) communicates with a giant perimedullar venous pouch.

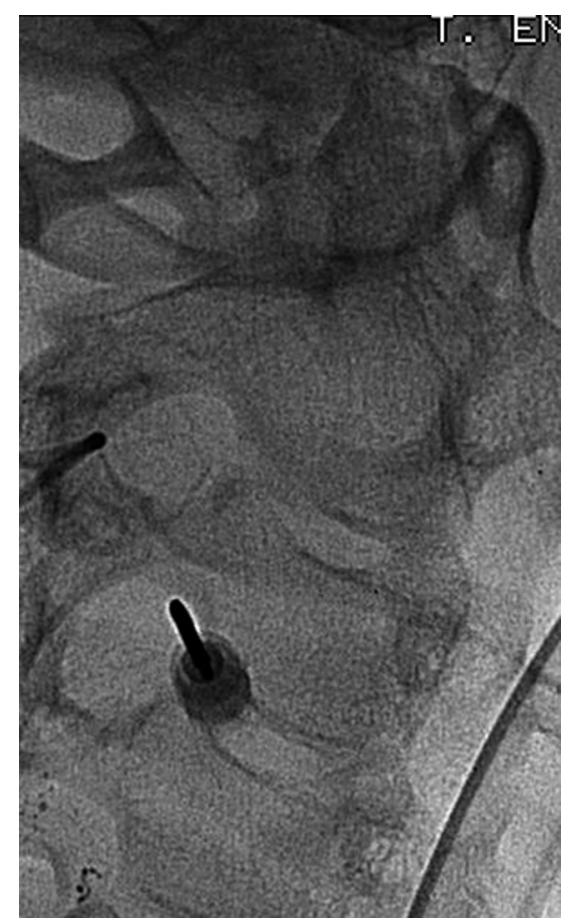

Fig 2. Percutaneous puncture of the venous pouch through the right $\mathrm{C} 3-\mathrm{C} 4$ neural foramen.

cedure, CT showed no evidence of subarachnoid or intraspinal hemorrhage and the presence of embolization material within the fistula and at the needle-placement site. Next, the patient was taken to the ICU for 24 hours, without deficit, and given dexamethasone, $4 \mathrm{mg} / 6$ hours IV and heparin, 10,000 U/24 hours IV. She was taken to a regular room the next day,

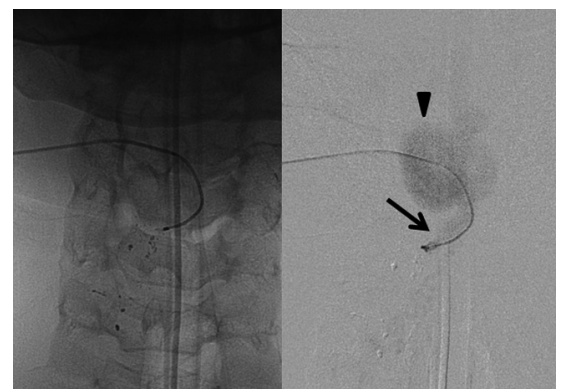

Fig 3. Cervical AP view of the draining vein through the microcatheter. We injected contrast material to corroborate the correct position of the microcatether, observing the beginning of the draining vein (arrow) and the venous pouch (arrowhead).

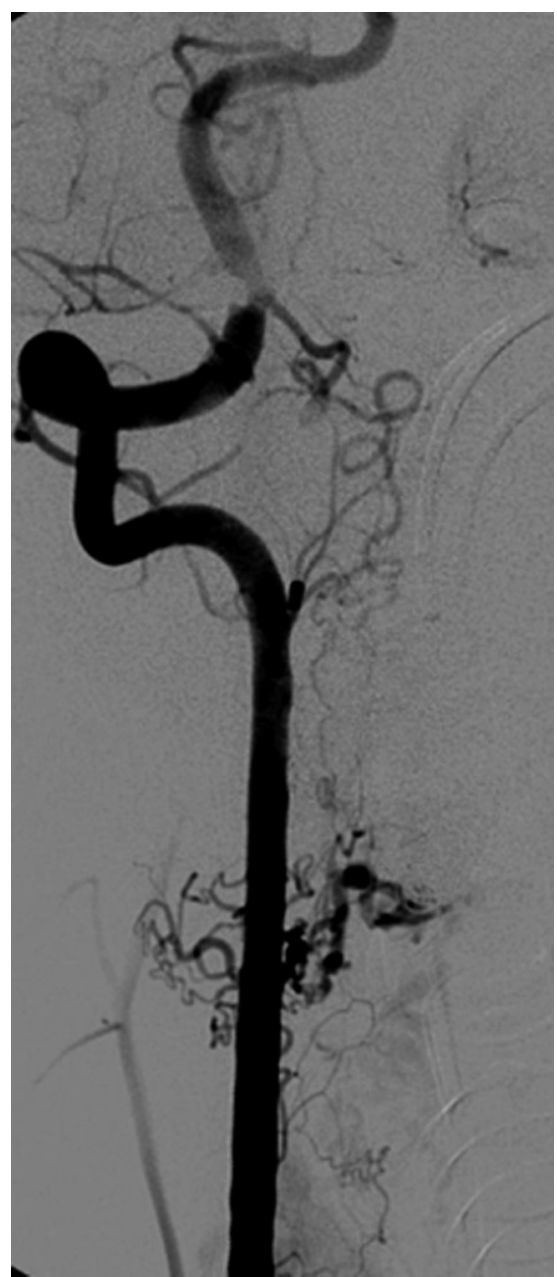

Fig 4. Postembolization DSA of the right vertebral artery shows complete disappearance of the AVM and patency of the radiculomedullary branches.

where she remained for the next 48 hours, and was discharged without deficit on dexamethasone, $3 \mathrm{mg} / 8$ hours, by mouth for 1 week. A control MR imaging was performed 3 months after the procedure, showing thrombosis of the venous pouch and decrease in the size of the perimedullary veins, with no alterations in the spinal cord. The patient remains asymptomatic.

\section{Case 2}

A 24-year-old woman had a history of subarachnoid hemorrhage years earlier characterized by meningeal symptoms and acute low back pain. A lumbar MR imaging was performed, 


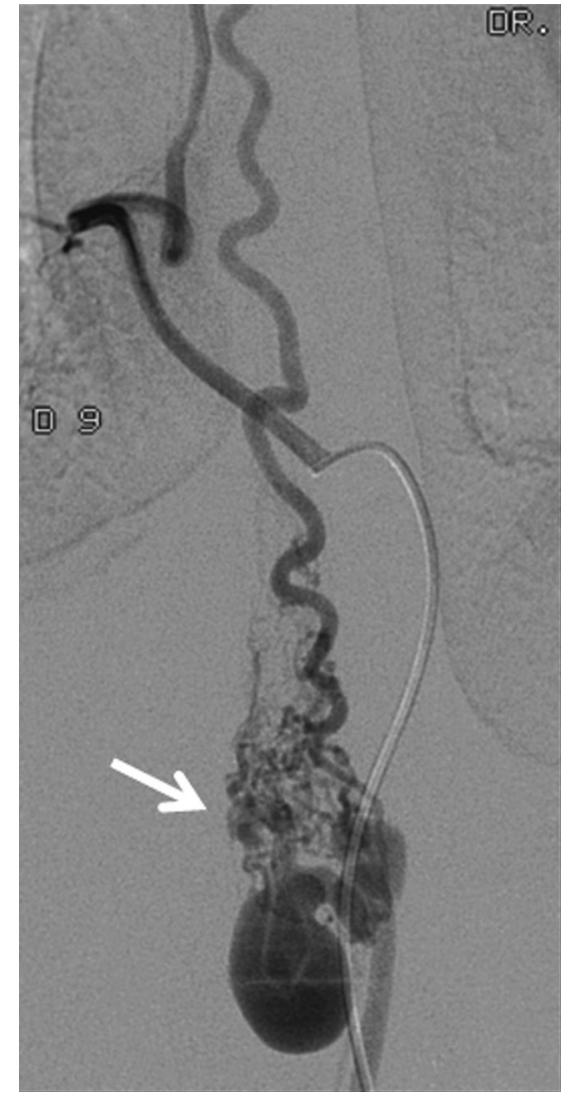

Fig 5. Selective DSA of the right T9 Intercostal artery shows a dilated anterior radiculomedullary artery that participates in the shunt through a network of pial branches that drain into a venous collector (white arrow) and a venous pouch.

revealing a spinal AVM at the conus medullaris. The diagnostic spinal angiography showed the AVM to be a giant PMAVF of the conus medullaris, with feeders from dilated anterior and posterior spinal arteries, both draining at the same point. The venous drainage was represented by a short dilated perimedullary vein that communicated with a right posterolateral venous pouch. The patient was treated with embolization of both arterial feeders with $n$-BCA, but the injection never reached the shunt. The symptoms improved after the embolization, but 1 month later, the pain started again, impeding her normal daily activities. A direct percutaneous puncture of the venous pouch and embolization of the venous collector were proposed.

With the patient under general anesthesia, in a supine position, a diagnostic angiography was performed via the right T9 femoral artery. The catheter was placed in the right T9 artery, from which arises an anterior radiculomedullary artery going to the shunt (Fig 5). The patient was moved to a left lateral decubitus position, and the venous pouch was reached under biplanar guidance and road-mapping with an 18-gauge Abbocath via percutaneous puncture through the interspinal space between T12 and L1 (Fig 6). The Abbocath was advanced to the center of the venous pouch until we had reflux of blood. We then injected contrast material and corroborated the position of the Abbocath in the center of the vein. A hemostatic valve was placed on the Abbocath, and an Echelon 14 microcatheter (ev3, Irvine, California) was used to catheterize the exact point at which the arterial feeders drained into the

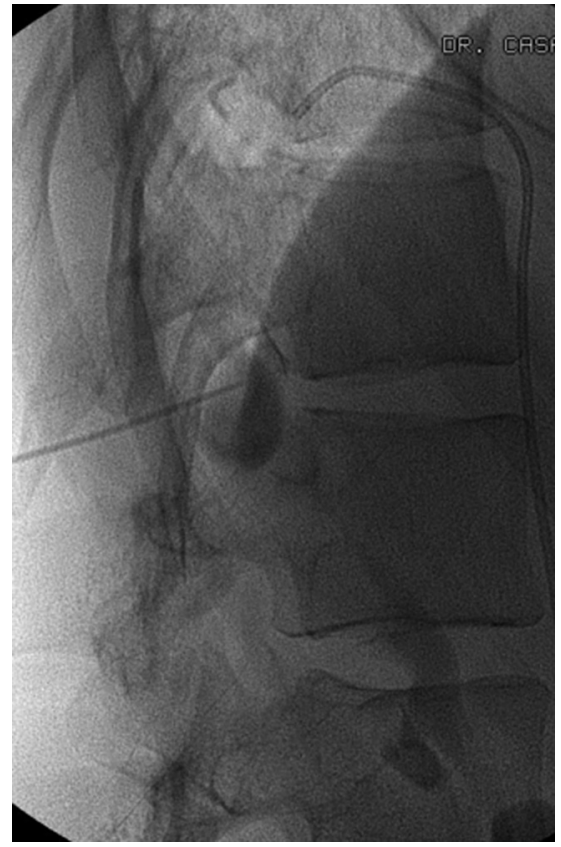

Fig 6. Puncture of the venous pouch through the T12-L1 interspinal space. Injection of contrast material opacifying the vein.

venous side. We placed coils to occlude the beginning of the draining vein and then completed the embolization by using Onyx 18 (ev3). Once the control angiography showed complete occlusion of the shunt with patency of all spinal arteries (Fig 7), we withdrew the Abbocath and the microcatheter and injected $n$-BCA at the same time to ensure immediate hemostasis of the puncture site.

The patient awoke from anesthesia without aggravation of her symptoms, and CT showed no spinal hemorrhage. She was taken to the ICU for 24 hours with the same management as in case 1. MR control imaging performed 3 months after the procedure showed complete thrombosis and reduction of the pouch. The patient had only right anterior tibial hypoesthesia and was able to return to her normal activities.

\section{Discussion}

From an angioarchitectural point of view, an AVF has the same anatomic and hemodynamic features, wherever it is located. Presently, the only way to cure an AVF is to eliminate the arteriovenous shunt. If the shunt cannot be eliminating via arterial or venous endovascular approaches, surgical resection may be the next option.

In cases of partial occlusion of the AVF and the technical impossibility of continuing embolization, we think surgery would be indicated, as long as it does not convey an excessive risk of medullar damage. In these 2 cases, the angioarchitecture of the shunt was very complex, and surgery had a high risk for a potential deficit.

Taking into account the superficial topography of the large venous pouches (anterolateral in the cervical level and posterolateral in the lumbar level) and after careful multidisciplinary discussion, we decided to attempt the direct percutaneous approach for these PMAVFs. Our team had previous experience with this kind of approach in the treatment of peripheral and craniofacial AVFs, and in both cases presented, 


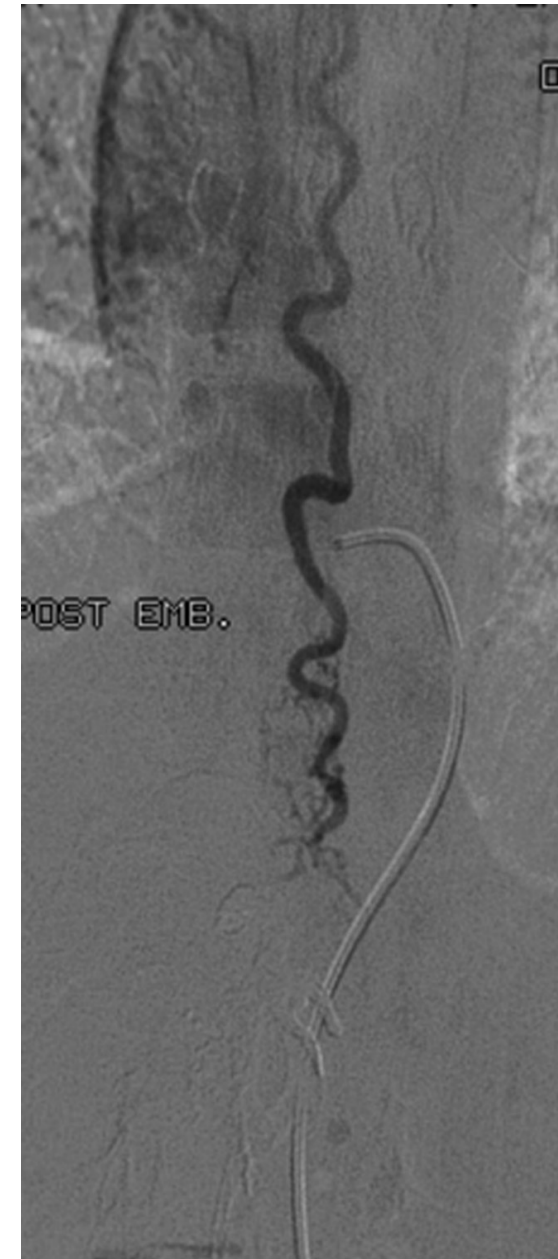

Fig 7. Postembolization DSA of the anterior spinal artery showing disappearance of the shunt at the lumbar level.

the venous pouch was in close proximity to the primary venous collector, allowing us to catheterize it in a short and simple way. We performed the puncture itself through the shortest route in a straight-through manner, choosing the transforaminal (cervical PMAVF) and interspinal (lumbar PMAVF) approaches.

The eventual risk of this approach could be the instability of the Abbocath, its accidental mobilization, or the inadvertent puncture of a dilated vessel on the way to the venous pouch and consequent hemorrhage. To avoid these potential risks, one must use simultaneous biplanar road-mapping and have the patient under general anesthesia, completely relaxed and immobilized. Both of our cases were performed with the neurosurgical team on standby, prepared for an emergency surgical resection in case of complications.

When a venous approach of an AVF is performed, either retrogradely or by direct puncture, coiling is very useful because it allows a more controlled injection of liquid embolization material, $n$-BCA, or Onyx, due to the hemodynamic changes produced by the coils. In the case of $n$-BCA, the presence of coils creates turbulence, which increases the polymerization time of the $n$-BCA, allowing higher dilutions with less risk of gluing the microcatheter, consequently also allowing slow and prolonged injections, as in the cervical PMAVF. In the lumbar PMAVF, we decided on Onyx 18 (ev3) as a liquid embolizing material to complement coiling. With Onyx, we
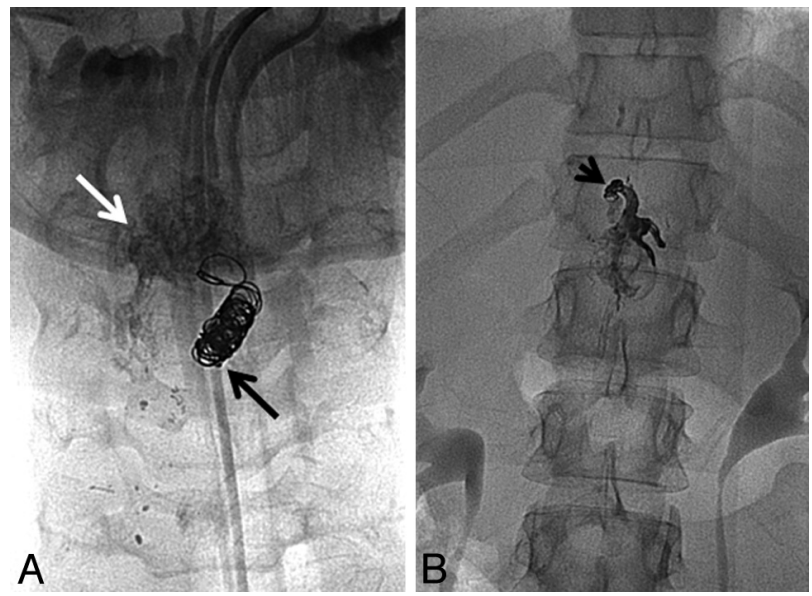

Fig 8. A, Cervical embolization with coils and cyanoacrylate. Coils are positioned at the beginning of the draining vein (black arrow), and the glue is injected into the venous pouch (white arrow). B, Lumbar AP view of the embolization material in the venous side of the shunt. Coils are identified in the primary collecting vein (black arrow), and in the rest of the vein and the venous pouch is Onyx 18

could control even more of the precision of the progressive occlusion of the draining vein (Fig 8).

Although the endovascular approach (arterial or venous) remains the standard of care for the management of giant PMAVFs, direct percutaneous venous puncture is feasible and can be another alternative minimally invasive treatment in cases in which arterial or retrograde venous approaches are not possible or are very risky. This technique should be performed by specialists highly trained in the treatment of spinal AVMs. The use of high-definition biplanar DSA is mandatory, as well as the collaboration of a multidisciplinary team for management and decision making. Only experience will tell us if this technique could, in the future, replace or be safer than traditional techniques for the treatment of giant PMAVFs.

\section{References}

1. Merland JJ, Riche MC, Chiras J. Intraspinal extramedullary arteriovenous fistulae draining into the medullary veins. J Neuroradiol 1980;7:271-320

2. Heros RC, Debrun GM, Ojemann RG, et al. Direct spinal arteriovenous fistula: a new type of spinal AVM-case report. J Neurosurg 1986;64:134-39

3. Gueguen B, Merland JJ, Riche MC, et al. Vascular malformations of the spinal cord: intrathecal perimedullary arteriovenous fistulas fed by medullary arteries. Neurology 1987;37:969-79

4. Kim LJ, Spetzler RF. Classification and surgical management of spinal arteriovenous lesions: arteriovenous fistulae and arteriovenous malformations. Neurosurgery 2006;59(5 suppl 3):S195-201, discussion S3-13

5. Houdart E, Gobin YP, Casasco A, et al. A proposed angiographic classification of intracranial arteriovenous fistulae and malformations. Neuroradiology 1993;35:381-85

6. Casasco AE, Houdart E, Gobin YP, et al. Embolization of spinal vascular malformations. Neuroimaging Clin N Am 1992;2:337-58

7. Barrow DL, Colohan AR, Dawson R. Intradural perimedullary arteriovenous fistulas (type IV spinal cord arteriovenous malformations). J Neurosurg 1994;81:221-29

8. Ricolfi F, Gobin PY, Aymard A, et al. Giant perimedullary arteriovenous fistulas of the spine: clinical and radiologic features and endovascular treatment. AJNR Am J Neuroradiol 1997;18:677-87

9. Rodesch G, Lasjaunias P. Spinal cord arteriovenous shunts: from imaging to management. Eur J Radiol 2003;46:221-32

10. Cho KT, Lee DY, Chung CK, et al. Treatment of spinal cord perimedullary arteriovenous fistula: embolization versus surgery. Neurosurgery 2005;56:232-41

11. Rodesch G, Hurth M, Alvarez H, et al. Embolization of spinal cord arteriovenous shunts: morphological and clinical follow-up and results-review of 69 consecutive cases. Neurosurgery 2003;53:40-49, discussion 49-50

12. Rodesch G, Hurth M, Alvarez H, et al. Spinal cord intradural arteriovenous fistulae: anatomic, clinical, and therapeutic considerations in a series of 32 consecutive patients seen between 1981 and 2000 with emphasis on endovascular therapy. Neurosurgery $2005 ; 57: 973-83$ 